\title{
Novel Toilet Paper-Based Point-Of-Care Test for the Rapid Detection of Fecal Occult Blood: Instrument Validation Study
}

Hsin-Yao Wang ${ }^{1,2^{*}}$, MD; Ting-Wei Lin ${ }^{1 *}$, MD; Sherry Yueh-Hsia Chiu ${ }^{3,4}$, PhD; Wan-Ying Lin ${ }^{5}$, MD; Song-Bin Huang $^{6}$, PhD; Jason Chia-Hsun Hsieh ${ }^{7,8}$, MD, PhD; Hsieh Cheng Chen ${ }^{6}$, MSc; Jang-Jih Lu ${ }^{1,9,10}$, MD, PhD; Min-Hsien $\mathrm{Wu}^{2,7,11,12}, \mathrm{PhD}$

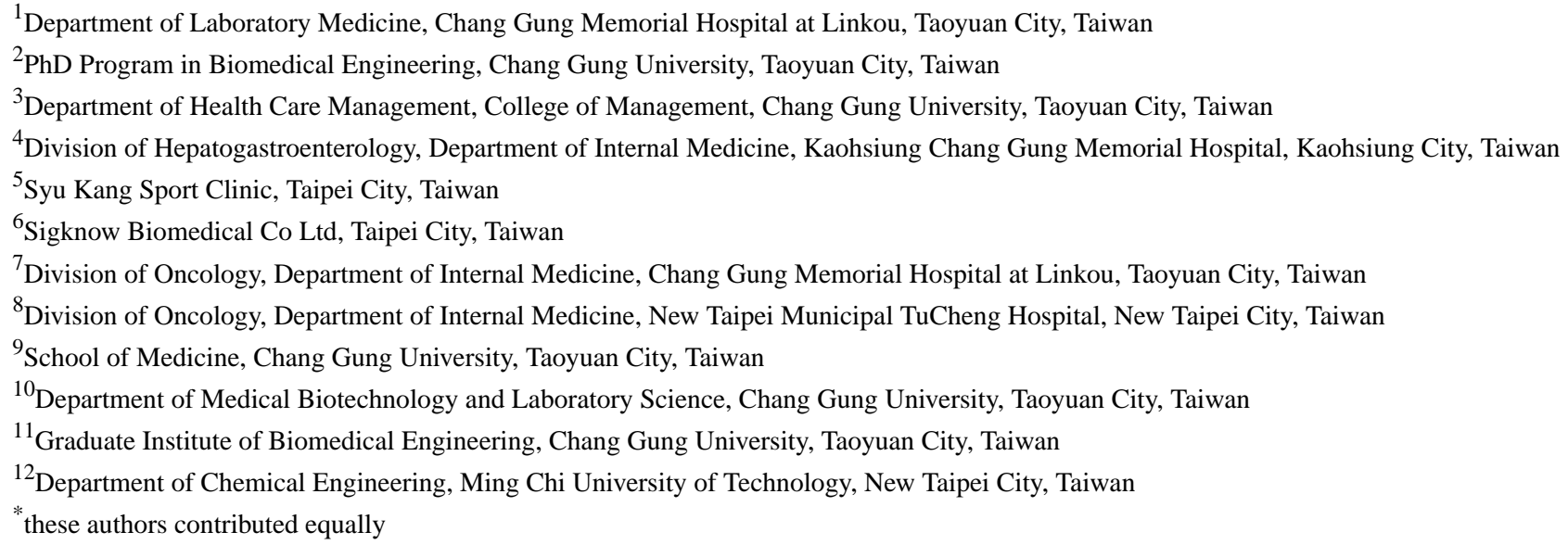

\section{Corresponding Author:}

Min-Hsien Wu, PhD

PhD Program in Biomedical Engineering

Chang Gung University

No. 259, Wenhua 1st Rd, Guishan Dist

Taoyuan City

Taiwan

Phone: 88632118800

Email:mhwu@mail.cgu.edu.tw

\section{Abstract}

Background: Colorectal cancer screening by fecal occult blood testing has been an important public health test and shown to reduce colorectal cancer-related mortality. However, the low participation rate in colorectal cancer screening by the general public remains a problematic public health issue. This fact could be attributed to the complex and unpleasant operation of the screening tool.

Objective: This study aimed to validate a novel toilet paper-based point-of-care test (ie, JustWipe) as a public health instrument to detect fecal occult blood and provide detailed results from the evaluation of the analytic characteristics in the clinical validation.

Methods: The mechanism of fecal specimen collection by the toilet-paper device was verified with repeatability and reproducibility tests. We also evaluated the analytical characteristics of the test reagents. For clinical validation, we conducted comparisons between JustWipe and other fecal occult blood tests. The first comparison was between JustWipe and typical fecal occult blood testing in a central laboratory setting with 70 fecal specimens from the hospital. For the second comparison, a total of 58 volunteers were recruited, and JustWipe was compared with the commercially available Hemoccult SENSA in a point-of-care setting.

Results: Adequate amounts of fecal specimens were collected using the toilet-paper device with small day-to-day and person-to-person variations. The limit of detection of the test reagent was evaluated to be $3.75 \mu \mathrm{g}$ of hemoglobin per milliliter of reagent. Moreover, the test reagent also showed high repeatability (100\%) on different days and high reproducibility (>96\%) among different users. The overall agreement between JustWipe and a typical fecal occult blood test in a central laboratory setting was $82.9 \%$. In the setting of point-of-care tests, the overall agreement between JustWipe and Hemoccult SENSA was $89.7 \%$. 
Moreover, the usability questionnaire showed that the novel test tool had high scores in operation friendliness (87.3/100), ease of reading results (97.4/100), and information usefulness (96.1/100).

Conclusions: We developed and validated a toilet paper-based fecal occult blood test for use as a point-of-care test for the rapid (in 60 seconds) and easy testing of fecal occult blood. These favorable characteristics render it a promising tool for colorectal cancer screening as a public health instrument.

(J Med Internet Res 2020;22(8):e20261) doi: 10.2196/20261

\section{KEYWORDS}

fecal occult blood test; point-of-care diagnostics; paper-based analytical devices; diagnostic; testing; detection; validation; cancer; public health

\section{Introduction}

Colorectal cancer ranks globally as the third-leading and second-leading cancer type in terms of incidence and mortality rates, respectively. The incidence rate of colorectal cancer continues to rise because of aging populations and lifestyle changes. The continuous increase in its incidence rate has brought considerable health burdens worldwide [1-3]. Clinically, early screening of colorectal cancer in average-risk persons has been shown to reduce both mortality and incidence [4-7]. A variety of screening methods, including fecal occult blood testing, fecal immunochemical-based testing, sigmoidoscopy, digital rectal examination, colonoscopy, and computed tomographic (CT) colonography, have been developed for colorectal cancer screening [8]. However, the overall screening rate is still low [2], especially in areas with limited resources $[9,10]$ or in socioeconomic minority groups [11-13]. In the United States, for example, the overall colorectal cancer screening rate was approximately $67.3 \%$ in 2016 [14]. In Taiwan, the screening rate was approximately $52.3 \%$ to $56.6 \%$ [15]. The low rate of colorectal cancer screening can be mainly attributed to the low availability, poor usability, or high cost of screening tools [9]. It is generally believed that the keys to successful implementation of colorectal cancer screening are cost-effectiveness, patient preference, and related professional medical resources $[4,16,17]$. Furthermore, it is important to provide flexibility and different choices for patients to conduct the examination themselves $[18,19]$.

Among the screening methods described earlier, flexible sigmoidoscopy and colonoscopy are the gold standard primary screening methods $[9,20,21]$ and can visually inspect the internal lining of the intestine [22]. By using endoscopy-based techniques, suspicious lesions or tumors can be detected, removed, and confirmed by pathology examination. However, scopy-based techniques require highly trained medical staff and specialized instruments. The operation of scopy-based instruments and the interpretation of the results are also highly operator dependent [23]. Moreover, the risks of scopy-based techniques include lower gastrointestinal bleeding, perforation, myocardial infarction, and ischemic stroke (approximately 5.3 per 10,000 persons; without biopsy or intervention, approximately 4.3 per 10,000 persons) [24,25]. CT colonography is a noninvasive exam for colorectal cancer screening with high sensitivity; it is comparable to colonoscopy [26,27]. Nevertheless, its widespread application is also limited by the availability of CT instruments and related facilities. High radiation exposure is another unfavorable feature of CT colonography [9,28]. Fecal occult blood tests and fecal immunochemical-based tests are both stool-based, noninvasive tests for colorectal cancer screening. Fecal occult blood testing targets heme, while fecal immunochemical-based testing detects hemoglobin in stool specimens. Studies have reported fecal immunochemical-based testing to have slightly higher performance than fecal occult blood testing in colorectal cancer screening [6,29]. However, the cost of fecal immunochemical-based testing is higher than that of fecal occult blood testing due to the expensive antihemoglobin antibody used in fecal immunochemical-based tests [30]. In terms of the successful implementation of colorectal cancer screening, fecal occult blood testing is the only screening method endorsed by the American Cancer Society to have the technical features of low cost and low medical profession requirements compared to other methods [6,31]. However, for current fecal occult blood testing, it is normally required that the test be performed by professional staff, restricting its application for point-of-care test or even home use. Moreover, current fecal occult blood tests generally require the user to collect fecal specimens using sticks to scoop stool after defecation. This unpleasant process could affect the widespread utilization of fecal occult blood tests for colorectal cancer screening [32-39].

To address this issue, we herein proposed a toilet paper-based fecal occult blood test (JustWipe) encompassing a toilet paper designed for fecal specimen collection and the reagents required for fecal occult blood test. For fecal specimen collection, we evaluated the working performance of the specially designed toilet paper. Moreover, we also developed and verified the analytical reagents used in the toilet paper-based tool. Based on the toilet paper design and analytical reagents, comparisons between the toilet paper-based tool and commercially available Hemoccult SENSA, as well as routine hospital fecal occult blood tests, were conducted to validate the new tool's clinical utility and show that by using the novel toilet paper-based fecal occult blood test, we could easily collect fecal specimens in a regular buttocks-wiping move after defecation and detect fecal occult blood rapidly and accurately.

\section{Methods}

\section{Design of the Toilet Paper-Based Fecal Specimen Collection Device}

The toilet paper-based fecal occult blood test (JustWipe; Sigknow Biomedical Co Ltd) contained the testing paper for 
fecal specimen collection and the necessary reagents, as illustrated in Figure 1. Briefly, the specimen collection device was designed as a toilet paper-based tool. The user sticks his or her fingers onto the specific adhesive area on the front side of the paper and collects fecal specimens on the back side of the toilet paper during an ordinary buttocks-wiping move. The reagent part contains the two developers required for testing occult blood in the fecal specimen. Specifically, the toilet paper for fecal specimen collection (width: $100 \mathrm{~mm}$, height: $140 \mathrm{~mm}$ ) was composed of leaf bleached kraft pulp, which is commonly used for ordinary toilet paper. The front side (ie, hand handle side) was designed as a circular adhesive area (diameter: 50 $\mathrm{mm}$ ) with a visual mark to facilitate correct handling of the tool (Figure 1 and Figure 2). The back side (ie, specimen collection side) was designed with a circular stool collection area (diameter: $50 \mathrm{~mm}$ ) composed of a water repellent polyester cloth for fecal specimen collection (Figure 1 and Figure 2).
Developer A contained 3,3',5,5'-tetramethylbenzidine, and developer B contained hydrogen peroxide and ethanol. For JustWipe, the steps are to stick fingers onto the circular area of the front side, wipe buttocks, and collect fecal specimens on the circular area on the back side, fold the device, and apply reagents (developer A and developer B) to develop the test reaction, whereas for typical fecal occult blood tests, the steps are to defecate, scoop stool with stick, spread the collected stool on the test zone, and apply reagent to develop the test reaction. The entire process for JustWipe is schematically illustrated in comparison with that of the conventional fecal occult blood test counterpart in Figure 3. When occult blood exists in the specimen, a blue-green color develops. In contrast, a typical guaiac-based fecal occult blood test (eg, Hemoccult Sensa; Beckman Coulter) would require additional feces collection and spreading using sticks.

Figure 1. Design of the toilet paper-based fecal occult blood point-of-care test (JustWipe). TMB: 3,3',5,5'-tetramethylbenzidine; $\mathrm{H}_{2} \mathrm{O}_{2}$ : hydrogen peroxide.

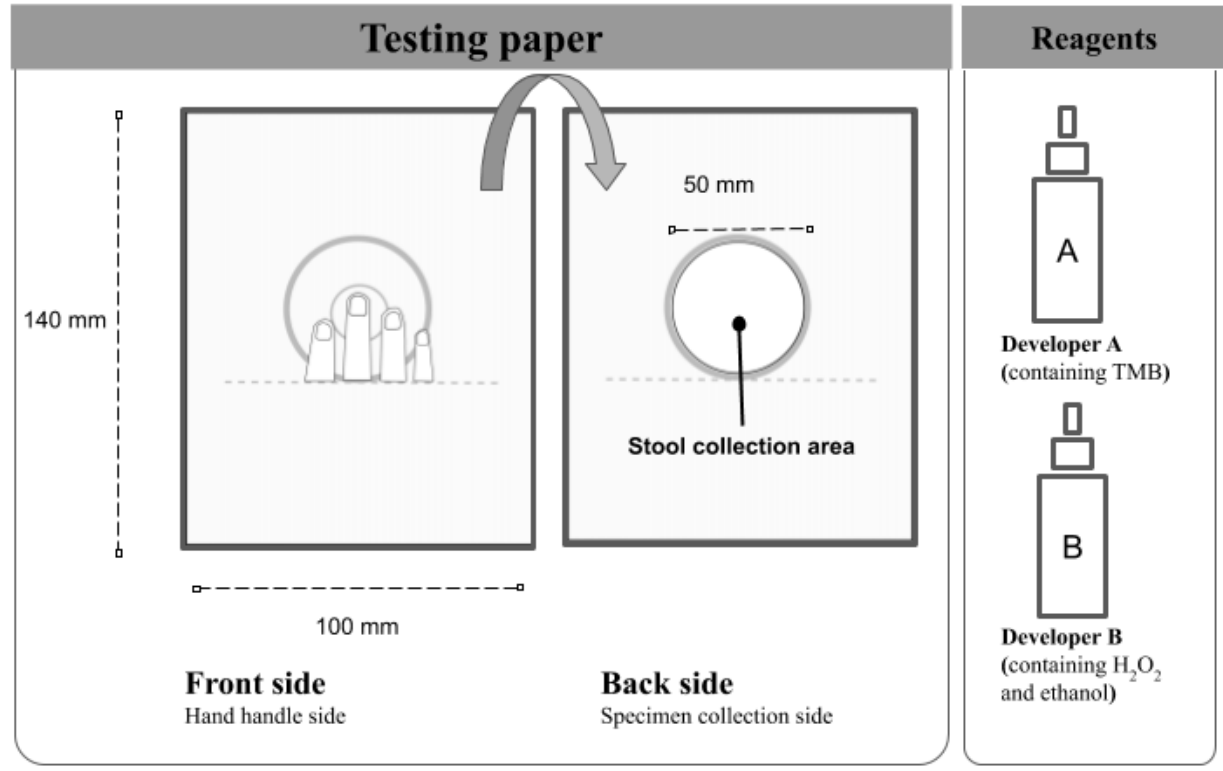


Figure 2. The appearance of the JustWipe: (A) The front side of the toilet testing paper with the hand handle side is clearly marked. (B) The backside of the toilet testing paper has a stool collection area with water repellent polyester cloth.
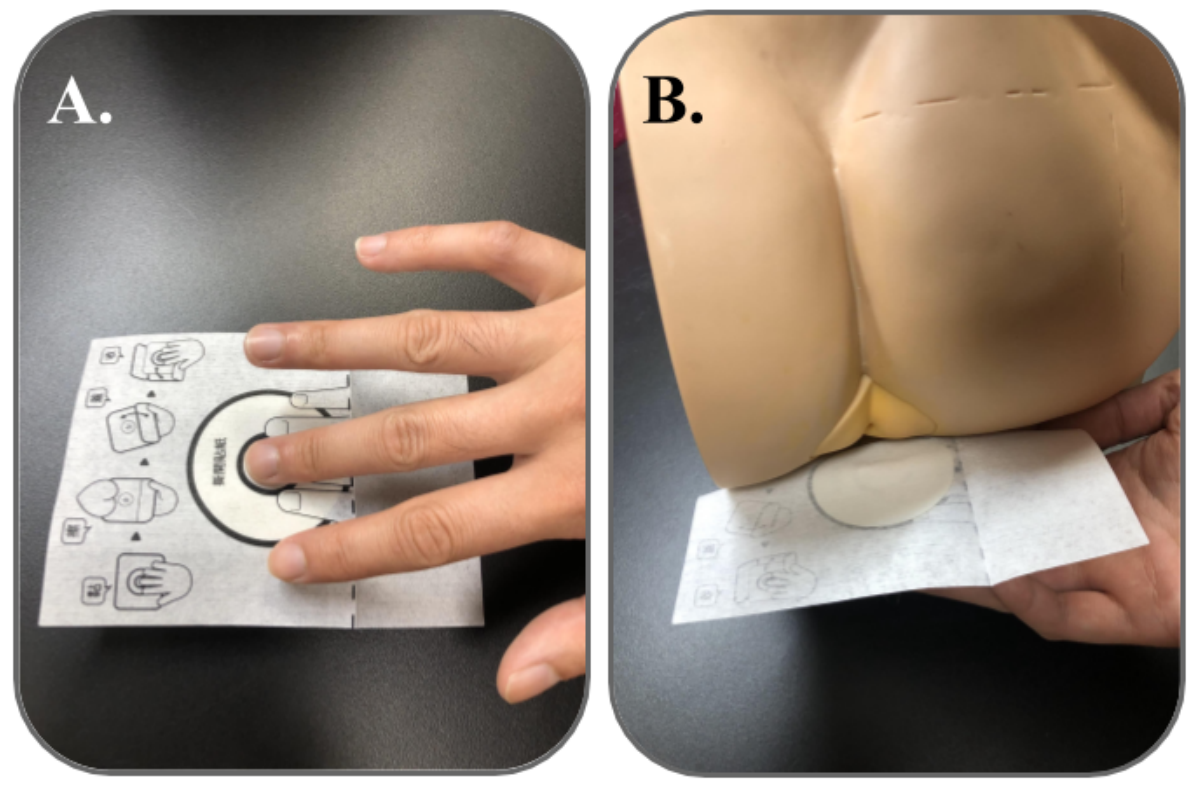

Figure 3. Comparison between JustWipe and typical fecal occult blood testing processes.

A. JustWipe

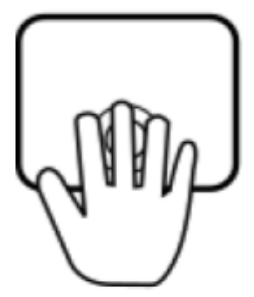

B. Typical FOBT
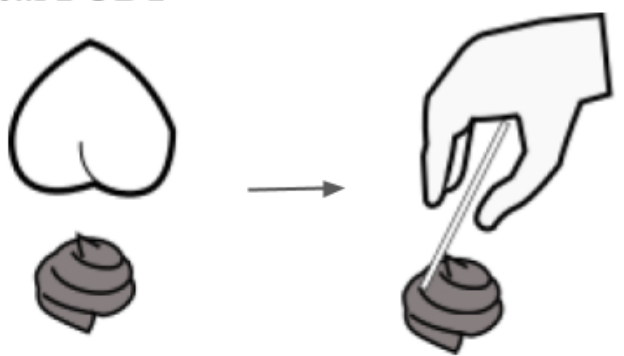

\section{Specimen Collection Performance of the Toilet Paper-Based Fecal Specimen Collection Device}

To examine the variation in specimen collection using the toilet paper-based fecal specimen collection, 18 volunteers were recruited for the evaluation. For three consecutive days, each volunteer collected a specimen after defecation using the JustWipe method directly with a testing paper device. The weight of the testing paper was measured before and after collecting the specimen. The specimen weight from the testing paper was calculated by subtracting the testing paper weight before wiping from the testing paper weight after wiping.
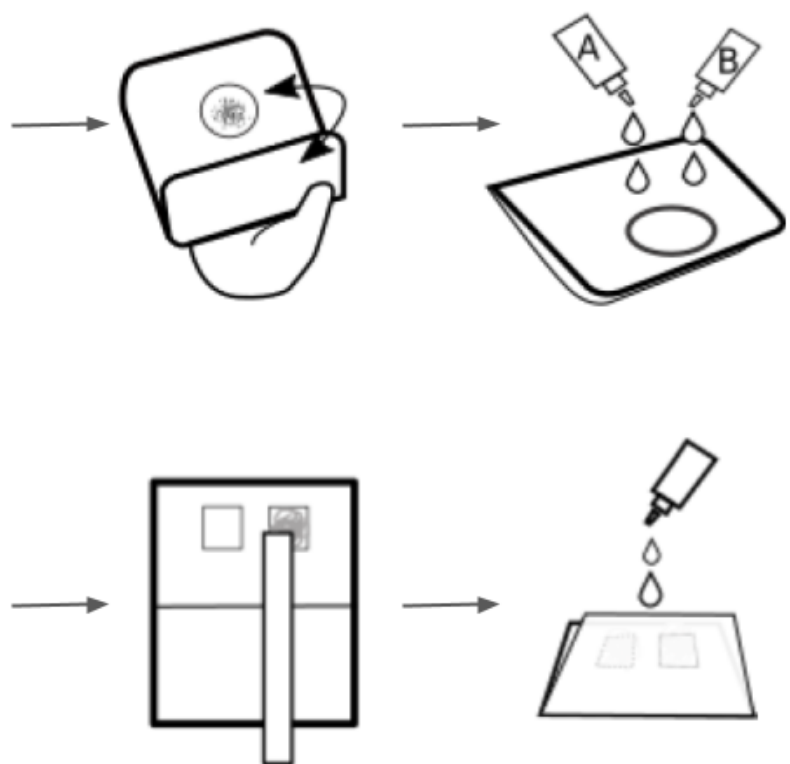

\section{Limit of Detection of the Testing Reagents}

We conducted a qualitative performance evaluation to determine the limit of detection of the reagents used in JustWipe according to Clinical and Laboratory Standards Institutes (CLSI) EP12-A2 User Protocol for Evaluation of Qualitative Test Performance [40]. Serial concentrations of hemoglobin solutions $(0 \mu \mathrm{g} / \mathrm{mL}$, $1.88 \mu \mathrm{g} / \mathrm{mL}, 2.26 \mu \mathrm{g} / \mathrm{mL}$, and $3.75 \mu \mathrm{g} / \mathrm{mL}$ ) consisting of human hemoglobin powder (Sigma-Aldrich) dissolved in double distilled water $\left(\mathrm{ddH}_{2} \mathrm{O}\right.$; Sigma-Aldric) were prepared. For each concentration, we applied $10 \mu \mathrm{L}$ of hemoglobin solution to the circular collection area on the back side of the specimen collection device and then covered the circular collection area 
by folding the paper. Subsequently, we added 2 drops $(80 \mu \mathrm{L})$ of reagent $A$ and 2 drops $(80 \mu \mathrm{L})$ of reagent $B$ to develop the reaction for 60 seconds. Tests for each hemoglobin concentration were replicated 160 times ( 40 times by $n=4$ operators).

\section{Intraassay and Interassay Repeatability of the Testing Reagents}

We evaluated both intraassay and interassay repeatability based on CLSI EP12-A2 [40]. We measured the performance of the testing reagents on different hemoglobin concentrations $(0$ $\mu \mathrm{g} / \mathrm{mL}, 3.75 \mu \mathrm{g} / \mathrm{mL}$, and $15 \mu \mathrm{g} / \mathrm{mL}$ ) on three different days. Each hemoglobin concentration was tested 9 times on each independent day. We applied $10 \mu \mathrm{L}$ of hemoglobin solution to the circular collection area on the back side of the specimen collection device and then covered the circular collection area by folding the paper. Subsequently, we added 2 drops $(80 \mu \mathrm{L})$ of reagent $A$ and 2 drops $(80 \mu \mathrm{L})$ of reagent $B$ to develop the reaction for 60 seconds. Tests of the same hemoglobin concentration performed on the same day were used to calculate the intraassay repeatability. In contrast, interassay repeatability was evaluated using the test results collected on different days.

\section{Reproducibility of the Testing Reagents in Untrained Users and Medical Staff}

The reproducibility between untrained users $(n=50)$ and trained medical staff $(n=2)$ using the test reagents was evaluated based on CLSI EP5-A3 Evaluation of Precision Performance of Quantitative Measurement Methods guidance [41]. Two concentrations of hemoglobin solution $(0 \mu \mathrm{g} / \mathrm{mL}$ and 3.75 $\mu \mathrm{g} / \mathrm{mL}$ ) were prepared and tested by the untrained users and trained medical staff. Each concentration of hemoglobin solution was tested twice.

\section{Performance Comparison Between JustWipe and the Typical Fecal Occult Blood Test in a Central Medical Laboratory}

We collected 70 convenience nonduplicate stool specimens from the central medical laboratory of Chang Gung Memorial Hospital Linkou branch between September 11, 2019 and March 24, 2020. The study was approved by the Institutional Review Board of Chang Gung Medical Foundation (No. 201901287B0). The stool specimens were collected in wards by nurses and placed into routine stool collection tubes [42]. The volume of the specimens was visually estimated to be greater than the size of a thumb. The specimens were deidentified before analytical measurements. An aliquot of stool was tested using a typical fecal occult blood test (O-tolidine test; Shin-Yung Medical Instruments Co Ltd). Another aliquot of stool was tested using JustWipe. The study design is illustrated in Figure 4.

Figure 4. Study design flowchart. FOBT: fecal occult blood test.

\section{Clinical Validation with Stool Samples}

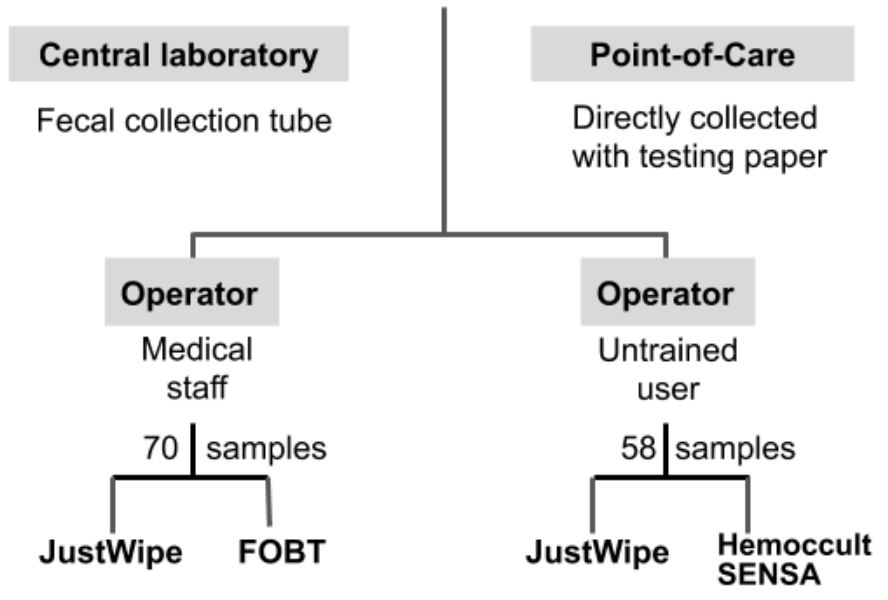

\section{Performance Comparison Between JustWipe (as a Point-of-Care Test) and Hemoccult Sensa}

We recruited 58 volunteers to use JustWipe as a point-of-care test in the period between March 1, 2019 and January 31, 2020. The volunteers were recruited from the Chang Gung Memorial Hospital and Chang Gung University. The study was approved by the Institutional Review Board of Chang Gung Medical Foundation (No. 201900133B0). The volunteers were asked to follow the instructions of JustWipe after defecation: the volunteer wiped his or her buttocks to collect stool specimens with the toilet paper-based fecal specimen collection device, followed by the steps of folding the device and applying the reagents. The volunteers interpreted the results themselves after 60 seconds of reaction. Subsequently, for testing with Hemoccult

SENSA, the volunteers collected the rest of the specimens (a volume greater than that of a thumb) and sent the specimens to the medical staff within 20 hours which were kept at room temperature or stored between $2{ }^{\circ} \mathrm{C}$ to $8{ }^{\circ} \mathrm{C}$ and shipped to the laboratory next day. For Hemoccult SENSA (Beckman Coulter), the stool specimens received by the laboratory were then tested by medical staff according to the instructions of Hemoccult SENSA.

\section{Usability and User Preference Evaluation of JustWipe}

The questionnaire was designed to assess the usability and user preference of the JustWipe. The questionnaire contained 12 questions about the user's experience of the toilet paper-based fecal occult blood test (Table 1). Each question had 5 different response options (strongly agree, agree, neutral, disagree, and 
strongly disagree), which reflected the volunteers' feedback on the usability of the test. The 58 recruited volunteers from the above study were requested to fill in the questionnaire by themselves after using JustWipe.

Table 1. Questionnaire used for usability evaluation. There were 12 questions on the questionnaire to assess the three aspects of the test, namely, operation friendliness, ease of reading the results, and information usefulness.

\begin{tabular}{|c|c|c|c|}
\hline Group & Number & Items & Average agreement, $\%$ \\
\hline \multirow[t]{5}{*}{ Information usefulness } & 1 & Did you know that the detection target is fecal occult blood? & 100 \\
\hline & 2 & Did you know that the testing result is not an indicator of cancer? & 98.6 \\
\hline & 3 & Did you know that the testing result is only for physical conditions? & 100 \\
\hline & 4 & Do you know what to do after testing? & 88.3 \\
\hline & 5 & If the test result is positive, would you go to the hospital for further examination? & 93.8 \\
\hline \multirow[t]{5}{*}{ Operational friendliness } & 6 & Are the two bottle designs easy to identify? & 89.0 \\
\hline & 7 & Do you understand all of the items in the device using the instruction manual? & 86.2 \\
\hline & 8 & Is detailed company information provided in the instruction manual? & 87.2 \\
\hline & 9 & Are all cautions clearly presented to the user? & 87.6 \\
\hline & 10 & Are the operational procedures clearly presented to the user through icons and words? & 86.9 \\
\hline \multirow[t]{2}{*}{ Ease of result reading } & 11 & Is your interpretation of the circle window the same as the medical staff's result? & 95.2 \\
\hline & 12 & Is your interpretation of the control area the same as the medical staff's result? & 99.7 \\
\hline
\end{tabular}

\section{Statistical Analysis}

We used a one-way analysis of variance (ANOVA) to test weight differences among specimens collected on different days. Kruskal-Wallis one-way ANOVA was used to test weight differences among specimens collected by different individuals. The statistical analysis of the two diagnostic test evaluation studies followed the statistical guidance on reporting results from studies evaluating diagnostic tests [43]. The $2 \times 2$ tables for each study were produced for comparisons between the index test method (ie, JustWipe) and the comparative methods. The estimation of the agreements included positive agreement, negative agreement, and overall agreement. Approximate 95\% confidence limits for the true overall, positive, and negative agreement were calculated as the estimated value \pm 2 standard error. The method for standard error calculation followed EP12-P from National Committee for Clinical Laboratory Standards [44].

\section{Results}

\section{Variation in Specimen Collection is Acceptable Among Different Individuals and Different Days}

We evaluated the variation of specimen collection when using the toilet paper-based fecal specimen collection device (Figure 5 ). Both between-day variation and between-individual variation were evaluated in 18 individuals. In total, the median specimen weight was $25 \mathrm{mg}$, and the interquartile range was $89 \mathrm{mg}$. The minimum specimen weight was $6 \mathrm{mg}$, and the maximum weight was $1897 \mathrm{mg}$. Regarding the between-day variation, there was no difference in the weight of specimens collected on the 3 different days $(P=.12)$. In contrast, a significant specimen weight difference was noted for different individuals. Specifically, 3 out of the 18 individuals collected a significantly greater amount (as a specimen) than the others did. When these 3 individuals were excluded, the statistical test showed no specimen weight differences among individuals. In summary, between-day variation was not significant. Between-individual variation was significant though, the outliers collected more specimen than the averages. 
Figure 5. Weight distribution and variation of fecal specimens that are collected among (A) different days and (B) different users.

A

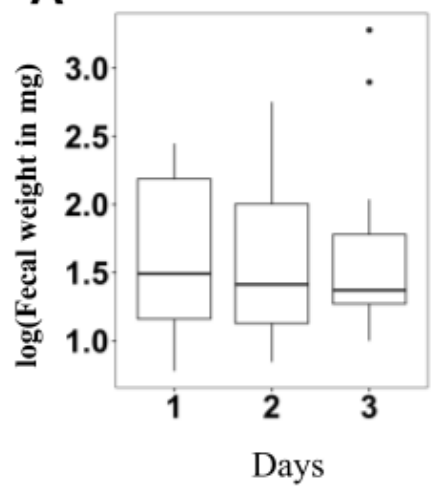

\section{Analytical Characteristics of the Test Reagents}

An imprecision curve of the analytical reagents used in JustWipe was used to illustrate the analytical characteristics (Figure 6). The probabilities of positive results for $2.26 \mu \mathrm{g} / \mathrm{mL}$ and 3.75 $\mu \mathrm{g} / \mathrm{mL}$ were $48.8 \%$ and $98.8 \%$, respectively. The concentration of $2.26 \mu \mathrm{g} / \mathrm{mL}$ could be defined as C50 (at which yielded $50 \%$ positive result and $50 \%$ negative result) for the test reagents [43]. The concentration of $3.75 \mu \mathrm{g} / \mathrm{mL}$ could be defined as the limit of detection (equal to C95) at which over $95 \%$ of the samples tested positive. The repeatability of testing different

B

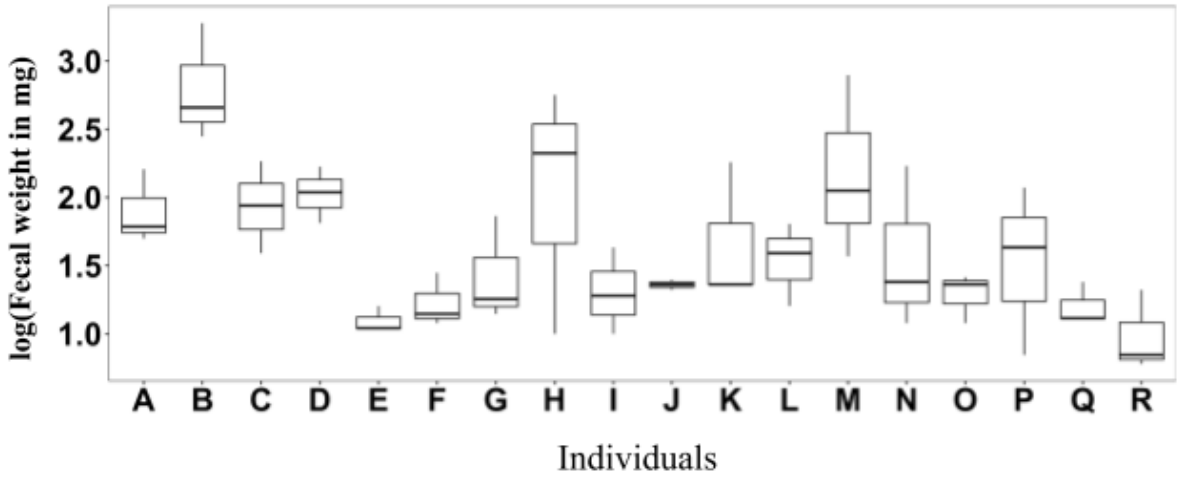

hemoglobin levels on different days is demonstrated in Figure 6 . The positive probabilities for $5 \mu \mathrm{g} / \mathrm{mL}$ and $15 \mu \mathrm{g} / \mathrm{mL}$ were $100 \%$ for each over the three days; for $0 \mu \mathrm{g} / \mathrm{mL}$, the positive probability was $0 \%$ over the three days. The repeatability for a longer period (20 days) is shown in Multimedia Appendix 1. Moreover, the reproducibility across untrained individuals and medical staff is illustrated in Figure 6. The trained users correctly operated all the samples whose concentrations were either $0 \mu \mathrm{g} / \mathrm{mL}$ or $3.75 \mu \mathrm{g} / \mathrm{mL}$; the untrained users correctly operated the samples of $0 \mu \mathrm{g} / \mathrm{mL}$, but the pass rate for 3.75 $\mu \mathrm{g} / \mathrm{mL}$ was $96.0 \%(48 / 50)$.

Figure 6. Analytical characteristics of the test reagents: (A) limit of detection, (B) positive probabilities for 5 and $15 \mu \mathrm{g} / \mathrm{mL}$, and (C) reproducibility among trained (medical staff) or untrained users.
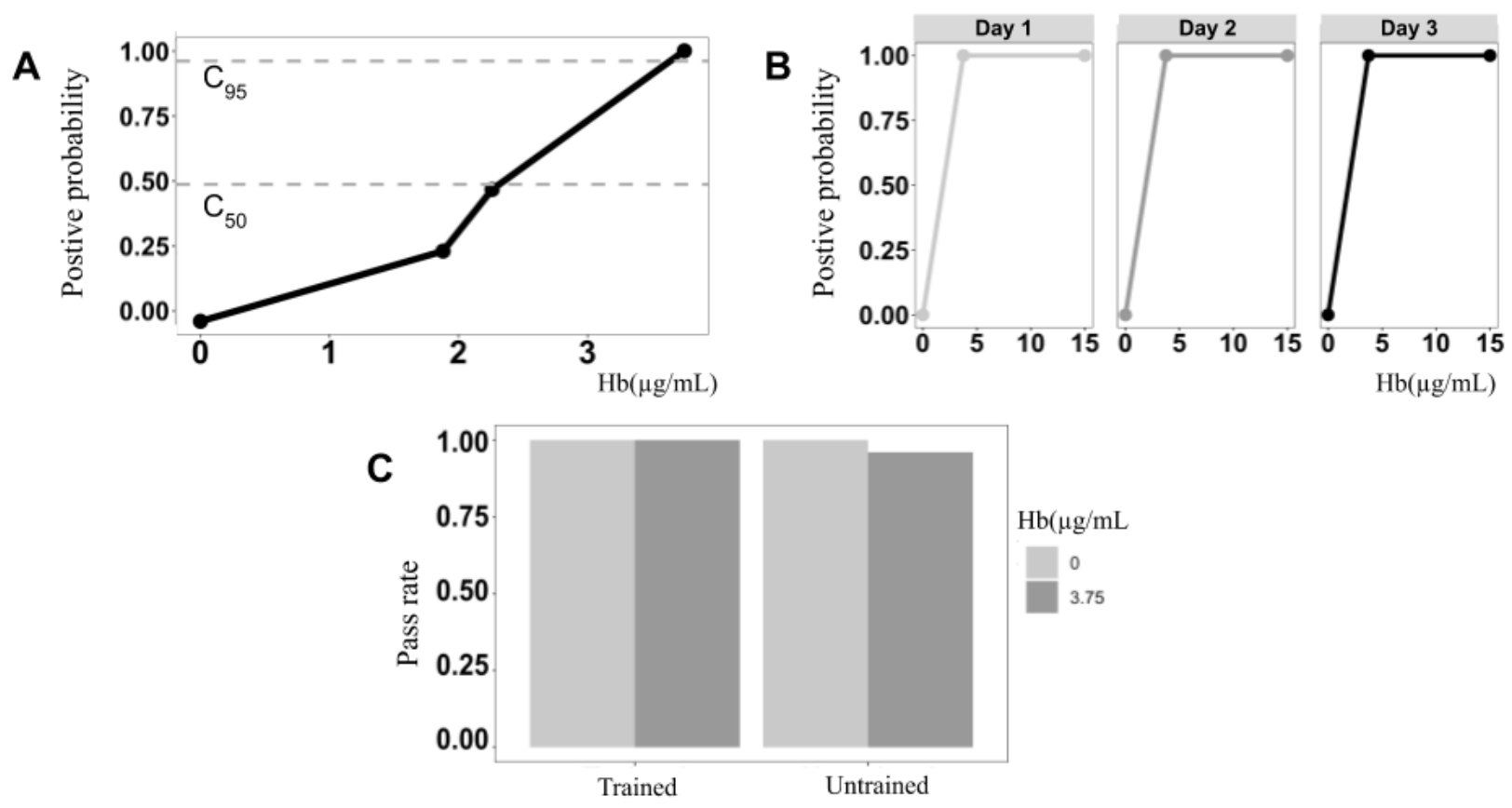

\section{Clinical Validation of JustWipe in a Central Laboratory Setting}

A comparison of the performance between JustWipe and a typical fecal occult blood test (O-tolidine-based test) was conducted using 70 clinical specimens collected in a tertiary

referral hospital. The overall agreement was $82.9 \%(52 / 70)$; the positive agreement and negative agreement were $83.9 \%(26 / 31)$ and $82.1 \%(32 / 39)$, respectively (Table 2). The qualitative test results of both methods can be found in Multimedia Appendix 2. 
Table 2. Performance comparison between JustWipe and a typical fecal occult blood test, and between JustWipe and Hemoccult SENSA.

\begin{tabular}{|c|c|c|c|c|c|c|}
\hline \multirow[t]{2}{*}{ Comparison } & \multicolumn{3}{|c|}{ Hospital fecal occult blood test } & \multicolumn{3}{|c|}{ Hemoccult SENSA } \\
\hline & Positive & Negative & Total & Positive & Negative & Total \\
\hline \multicolumn{7}{|l|}{ JustWipe, n } \\
\hline Positive & 26 & 7 & 33 & 16 & 2 & 18 \\
\hline Negative & 5 & 32 & 37 & 4 & 36 & 40 \\
\hline Total & 31 & 39 & 70 & 20 & 38 & 58 \\
\hline \multicolumn{7}{|l|}{ Agreement, \% } \\
\hline Estimate $\left(95 \% \mathrm{CL}^{\mathrm{a}}\right)$ & $83.9(70.7,97.1)$ & $82.1(69.8,94.3)$ & $82.9(73.9,91.9)$ & $80.0(62.1,80.0)$ & $94.7(87.5,102)$ & $89.7(81.7,97.7)$ \\
\hline
\end{tabular}

${ }^{\mathrm{a}} 95 \%$ confidence limits calculated as (estimate -2 standard error, estimate +2 standard error).

\section{Validation of JustWipe as a Point-Of-Care Test}

The intended use of JustWipe is testing occult blood in the stool at home or at a point of care. Thus, we evaluated the performance of JustWipe when it was used as a point-of-care test according to the manufacturer's instructions. The overall agreement was $89.7 \%(52 / 58)$; the positive agreement and negative agreement were $80.0 \%(16 / 20)$ and $94.7 \%(36 / 38)$, respectively (Table 2). The qualitative test results of both methods can be found in Multimedia Appendix 3.

\section{Usability and User Preference Evaluation of JustWipe}

Of the 58 volunteers, there were $32(55.2 \%)$ women and 26 $(44.9 \%)$ men. The average age of the volunteers was 59.1 (SD 12.7) years. We asked the volunteers to complete the questionnaire (12 questions included) after using JustWipe as a point-of-care test. We summarized the results of the questionnaire into three categories: information usefulness (Q1, Q2, Q3, Q4, and Q5), operational friendliness (Q6, Q7, Q8, Q9, and Q10), and ease of reading results (Q11 and Q12). In terms of information usefulness, average agreement percentages for Q1, Q2, Q3, Q11, and Q12 were 100\%, 98.6\%, 100\%, 88.3\%, and $93.8 \%$, respectively. In the category of operational friendliness, average agreement percentages for Q6, Q7, Q8, Q9, and Q10 were 89\%, 86.2\%, 87.2\%, 87.6\%, and 86.9\%, respectively. For the category of ease of reading results, Q11 had an average of $95.2 \%$ and Q12 had an average of $99.7 \%$.

\section{Discussion}

\section{Principal Findings}

In this study, we developed a toilet paper-based point-of-care test (JustWipe) for the rapid detection of fecal occult blood. An ordinary buttocks-wiping move on the toilet was adapted as the mechanism of stool specimen collection. Specimen collection by buttocks-wiping was evaluated to be useful and stable. In addition, a set of test reagents was developed and characterized. We compared the performance of JustWipe with that of a typical fecal occult blood test in a central laboratory setting. Moreover, we also demonstrated the performance of JustWipe as a point-of-care test. Based on the toilet paper-based device, stool specimens can be collected with a regular buttocks-wiping move. A rapid test result is available within 60 seconds using the test reagents. An ordinary user can operate the test easily, rapidly, and with reproducibility. The ease of operation and reliability render the novel fecal occult blood test a promising tool for colorectal cancer screening.

Troublesome operation of stool specimen collection is considered one of the obstacles affecting participation in colorectal cancer screening [13,32,34,36,37,39]. In a typical fecal occult blood test, fecal immunochemical-based test, or other stool-based occult blood tests, stool specimen collection is difficult. Users, typically with a nonmedical background, must sample stool by themselves. Several steps, including flushing the toilet bowl and floating tissue paper on the surface of the toilet bowl water, are required to be followed and performed correctly to ensure the quality of the specimen [45]. The users must also collect stool samples before it comes into contact with the toilet bowl water [45]. The demanding requirements not only reduce willingness to use the device but also result in some analytical errors when some of the steps are not performed correctly. In contrast, the fecal specimen collection using JustWipe requires a regular buttocks-wiping move only. The number of steps in fecal specimen collection is reduced so that the errors occurring in specimen collection can be largely mitigated. Moreover, the toilet paper-based stool specimen collection was shown to be stable between days and among different users (Figure 5). The mean and median weights of the stool specimens were $120.00 \mathrm{mg}$ and $25.50 \mathrm{mg}$, respectively. The amount of specimen collected was higher than that collected via typical methods. The relationship between the amount of stool specimen to test sensitivity is not clear. However, a larger amount collected as a specimen is thought to be an advantageous feature for a test [46].

The analytical evaluation of the test reagents used in JustWipe demonstrated several favorable characteristics, including high sensitivity, high repeatability, and high reproducibility. Low-concentration hemoglobin could be detected with minimal day-to-day variation (high repeatability) and person-to-person variation (high reproducibility). Regarding the analytical sensitivity of the test reagents, the test reagents were found to have adequate analytical sensitivity to detect occult fecal blood in colorectal cancer patients. In a population study including 5.8 million individuals, a hemoglobin concentration of approximately $20 \mu \mathrm{g} / \mathrm{mL}$ could detect colorectal cancer with a detection rate of $5.2 \%$ in men and $2.2 \%$ in females. The hemoglobin concentration for the colorectal cancer patients identified in that study was between 172.8 and $231 \mu \mathrm{g}$ hemoglobin/g feces [47]. In another study, a cut-off of 80-90 
$\mu \mathrm{g}$ hemoglobin/g feces was sufficient for clinical application [48-50]. Based on the reported values (ie, 80-90 $\mu \mathrm{g}$ hemoglobin/g feces), a cut-off of 114.3-128.6 $\mu \mathrm{g}$ hemoglobin $/ \mathrm{mL}$ is clinically useful when the water content in stool is $70 \%$ [51]. In contrast, the hemoglobin concentration in the feces of healthy individuals without colorectal cancer is $0.519 \mu \mathrm{g}$ hemoglobin/mL (90\% CI 0.468-0.575) in men and $0.283 \mu \mathrm{g}$ hemoglobin/mL (90\% CI $0.257-0.316)$ in women $[50,52,53]$. In brief, the limit of detection $(3.75 \mu \mathrm{g}$ hemoglobin $/ \mathrm{mL}$ ) of the test reagents of toilet paper-based tool was sensitive and stable enough for detecting fecal occult blood in colorectal cancer patients (Figure 6).

We validated JustWipe in the settings of a central laboratory and point of care. In both settings, JustWipe showed high agreement with typical test methods. In the setting of the central laboratory, both JustWipe and the comparative test (O-tolidine-based fecal occult blood test) were performed by medical staff. The positive agreement $(83.9 \%)$ and negative agreement $(82.1 \%$ ) were quite balanced (Table 2). In contrast, the positive agreement $(80.0 \%)$ was significantly lower than the negative agreement $(94.7 \%)$ when we validated JustWipe used as a point-of-care test (Table 2). To validate JustWipe as a point-of-care test, the comparative method (Hemoccult SENSA) was operated by medical staff, while JustWipe was operated by nonmedical individuals. Regarding the association between the usability and the discordance between positive and negative agreement of the test results, we used Fisher exact test for the analysis. The results in Multimedia Appendix 4 showed that the usability indicators (Table 1) were not associated with the discordance of the test results. The specific usability indicators should have been associated with the discordant results. However, based on our data, the significant association was not detected in the study. The nonsignificant association could be attributed to the relatively small sample size used in the proof-of-concept validation. Yet, the association is worthy of further investigation as a key for improving the proposed device. Furthermore, the possible cause for the suboptimal positive agreement could be attributed to false negative interpretation of the weak positive reaction. Users who are not trained medical professionals may tend to ignore the weak signal on the toilet paper. To address the limitation of interpretation, especially in the weak positive case, we plan to develop an artificial intelligence-aided interpretation tool. By using the artificial intelligence-aided interpretation tool, images of the test result can be interpreted with a standardized approach. The interpretative error resulting from insufficient interpretation experience would be largely mitigated. We illustrate the approach in Multimedia Appendix 5.

The major aim of designing JustWipe was to improve the usability of fecal occult blood testing. We assessed the usability of JustWipe using a questionnaire (Table 1). The categories of operational friendliness and ease of reading results are important indicators for a nonmedical professional using a point-of-care test [37,39]. Regarding operational friendliness, the agreement of all the questions (Q6, Q7, Q8, Q9, and Q10) was greater than $80 \%$ (range $81.9 \%-84.5 \%$ ). For ease of reading results (Q11 and Q12), the agreement was greater than 94\%. In brief, the high agreement in operational friendliness and ease of reading results indicated that users without professional medical training can easily operate the tool and interpret it following the instructions.

\section{Limitations}

Although the volunteers from our trial in the point-of-care test setting would be representative of the target population with respect to the range of age, sampling bias could still exist in the validation setting for the point-of-care test trial. All volunteers were recruited from the urban region in northern Taiwan. The average age of the recruited volunteers in the point-of-care test was 59.1 (SD 12.7) years. The range of age was approximately the age of the target population for most cancer screening programs. In the majority of Europe, the colorectal cancer prevention program recommends screening for people above 50 years old [54]. The US Preventive Services Task Force also recommend screening the population above 50 years old [6]. The colorectal cancer screening program in Taiwan also recommends screening for the population above 50 years old [55]. In this study, the volunteers were recruited from one tertiary medical center (ie Chang Gung Memorial Hospital, Linkou branch) and one university (ie, Chang Gung University). The volunteers may have had chronic diseases and subclinical conditions. The preliminary validation results reported in the study could not be easily applied to other populations. The performance using the proposed device in general population needs further investigation in a larger cohort. The demographic characteristics of the 58 recruited volunteers are listed in Multimedia Appendix 6.

\section{Conclusions}

We developed and validated a toilet paper-based point-of-care test for detecting fecal occult blood. The result showed that the toilet paper-based collection of fecal specimens was stable. The test reagents of the point-of-care test also showed high repeatability and reproducibility. The novel toilet paper-based point-of-care test revealed high agreement with the comparative methods in both central laboratory and point-of-care test settings. The usability evaluation of the point-of-care test showed high operation friendliness and high ease of reading results. The favorable characteristics render the proposed novel point-of-care test a promising colorectal cancer screening tool.

\section{Acknowledgments}

This work was edited by American Journal Experts. This work was supported by Sigknow Biomedical Co Ltd (SCRPD2I0011) and Chang Gung Memorial Hospital (CMRPD2J0031-33). 


\section{Authors' Contributions}

H-YW conceptualized the study. H-YW and T-WL wrote the manuscript, analyzed the data, plotted the figures, and created the tables. S-BH and HCC performed the experiments. SY-HC and J-JL reviewed and edited the manuscript for important intellectual content. M-HW obtained funding and supervised the study. All authors discussed the results and revised the manuscript.

\section{Conflicts of Interest}

This work was supported by Sigknow Biomedical Co Ltd (SCRPD2I0011). S-BH and H-CC were the employees of the Sigknow Biomedical Co Ltd.

\section{Multimedia Appendix 1}

Repeatability for a longer period (20 days) for the analytical characteristics of the test reagents.

[DOCX File , 69 KB-Multimedia Appendix 1]

\section{Multimedia Appendix 2}

Qualitative test results for both methods in the central laboratory.

[DOCX File , 54 KB-Multimedia Appendix 2]

\section{Multimedia Appendix 3}

Qualitative test results for both methods in the point-of-care test setting.

[DOCX File , $60 \mathrm{~KB}-$ Multimedia Appendix 3]

\section{Multimedia Appendix 4}

Association between individual usability indicators and result discordancy. The table showed the contingency table for each question on recruited volunteers with discordance and concordance result.

[DOCX File, 292 KB-Multimedia Appendix 4]

\section{Multimedia Appendix 5}

Using the mobile device for interpretation of test results. The workflow demonstrates how to use a mobile phone to assist interpretation with artificial intelligence model prediction.

[PNG File, 38 KB-Multimedia Appendix 5]

\section{Multimedia Appendix 6}

This table contains the demographic characteristics of age, gender, education, and occupation of the recruited volunteers. [DOCX File, $291 \mathrm{~KB}-$ Multimedia Appendix 6]

\section{References}

1. Favoriti P, Carbone G, Greco M, Pirozzi F, Pirozzi R, Corcione F. Worldwide burden of colorectal cancer: a review. Updates Surg 2016 Mar 11;68(1):7-11. [doi: 10.1007/s13304-016-0359-y] [Medline: 27067591]

2. Keum N, Giovannucci E. Global burden of colorectal cancer: emerging trends, risk factors and prevention strategies. Nat Rev Gastroenterol Hepatol 2019 Dec;16(12):713-732. [doi: 10.1038/s41575-019-0189-8] [Medline: 31455888]

3. Bray F, Ferlay J, Soerjomataram I, Siegel RL, Torre LA, Jemal A. Global cancer statistics 2018: GLOBOCAN estimates of incidence and mortality worldwide for 36 cancers in 185 countries. CA Cancer J Clin 2018 Sep 12;68(6):394-424 [FREE Full text] [doi: 10.3322/caac.21492] [Medline: 30207593 ]

4. Levin TR, Corley DA, Jensen CD, Schottinger JE, Quinn VP, Zauber AG, et al. Effects of organized colorectal cancer screening on cancer incidence and mortality in a large community-based population. Gastroenterology 2018 Nov;155(5):1383-1391.e5 [FREE Full text] [doi: 10.1053/j.gastro.2018.07.017] [Medline: 30031768]

5. Winawer SJ. The history of colorectal cancer screening: a personal perspective. Dig Dis Sci 2015 Mar;60(3):596-608. [doi: 10.1007/s10620-014-3466-y] [Medline: 25599958]

6. Lin JS, Piper MA, Perdue LA, Rutter CM, Webber EM, O'Connor E, et al. Screening for colorectal cancer: updated evidence report and systematic review for the US Preventive Services Task Force. JAMA 2016 Jun 21;315(23):2576-2594. [doi: 10.1001/jama.2016.3332] [Medline: 27305422]

7. Mandel JS, Bond JH, Church TR, Snover DC, Bradley GM, Schuman LM, et al. Reducing mortality from colorectal cancer by screening for fecal occult blood. N Engl J Med 1993 May 13;328(19):1365-1371. [doi: 10.1056/nejm199305133281901] 
8. PDQ Screening and Prevention Editorial Board. Colorectal cancer screening (PDQ). PDQ Cancer Information Summaries Internet National Cancer Institute (US).: National Cancer Institute; 2020 Mar 17. URL: https://www.ncbi.nlm.nih.gov/ books/NBK65825/ [accessed 2020-03-19]

9. Schreuders EH, Ruco A, Rabeneck L, Schoen RE, Sung JJY, Young GP, et al. Colorectal cancer screening: a global overview of existing programmes. Gut 2015 Oct;64(10):1637-1649 [FREE Full text] [doi: 10.1136/gutjnl-2014-309086] [Medline: 26041752]

10. Beeker C, Kraft JM, Southwell BG, Jorgensen CM. Colorectal cancer screening in older men and women: qualitative research findings and implications for intervention. J Community Health 2000 Jun;25(3):263-278. [doi: 10.1023/a:1005104406934] [Medline: 10868818]

11. Klabunde C, Blom J, Bulliard J, Garcia M, Hagoel L, Mai V, et al. Participation rates for organized colorectal cancer screening programmes: an international comparison. J Med Screen 2015 Sep;22(3):119-126. [doi:

10.1177/0969141315584694] [Medline: 25967088]

12. de Klerk CM, Gupta S, Dekker E, Essink-Bot ML, Expert Working Group 'Coalition to reduce inequities in colorectal cancer screening' of the World Endoscopy Organization. Socioeconomic and ethnic inequities within organised colorectal cancer screening programmes worldwide. Gut 2018 Apr;67(4):679-687. [doi: 10.1136/gutjnl-2016-313311] [Medline: 28073892]

13. Dawidowicz S, Le Breton J, Moscova L, Renard V, Bercier S, Brixi Z, et al. Predictive factors for non-participation or partial participation in breast, cervical and colorectal cancer screening programmes. Fam Pract 2020 Feb 19;37(1):15-24. [doi: 10.1093/fampra/cmz031]

14. Joseph DA, King JB, Richards TB, Thomas CC, Richardson LC. Use of colorectal cancer screening tests by state. Prev Chronic Dis 2018 Jun 14;15:E80 [FREE Full text] [doi: 10.5888/pcd15.170535] [Medline: 29908051]

15. Wang Y, Chen H, Wu M, Chiu H, Taiwanese Nationwide Colorectal Cancer Screening Program. Current status and future challenge of population-based organized colorectal cancer screening: Lesson from the first decade of Taiwanese program. J Formos Med Assoc 2018 May;117(5):358-364 [FREE Full text] [doi: 10.1016/j.jfma.2017.09.010] [Medline: 28988890]

16. Lieberman D, Ladabaum U, Cruz-Correa M, Ginsburg C, Inadomi JM, Kim LS, et al. Screening for colorectal cancer and evolving issues for physicians and patients: a review. JAMA 2016 Nov 22;316(20):2135-2145. [doi:

10.1001/jama.2016.17418] [Medline: 27893135]

17. Dougherty MK, Brenner AT, Crockett SD, Gupta S, Wheeler SB, Coker-Schwimmer M, et al. Evaluation of interventions intended to increase colorectal cancer screening rates in the united states: a systematic review and meta-analysis. JAMA Intern Med 2018 Dec 01;178(12):1645-1658 [FREE Full text] [doi: 10.1001/jamainternmed.2018.4637] [Medline: 30326005]

18. Denters MJ, Deutekom M, Bossuyt PM, Fockens P, Dekker E. A feces collection paper does not enhance participation in a fecal immunochemical test-based colorectal cancer screening program. European Journal of Cancer Prevention 2013;22(4):299-304 [FREE Full text] [doi: 10.1097/cej.0b013e32835b3882]

19. Quick BW, Hester CM, Young KL, Greiner KA. Self-reported barriers to colorectal cancer screening in a racially diverse, low-income study population. J Community Health 2013 Apr;38(2):285-292. [doi: 10.1007/s10900-012-9612-6] [Medline: $\underline{22976770]}$

20. Wolf AMD, Fontham ETH, Church TR, Flowers CR, Guerra CE, LaMonte SJ, et al. Colorectal cancer screening for average-risk adults: 2018 guideline update from the American Cancer Society. CA Cancer J Clin 2018 Jul;68(4):250-281 [FREE Full text] [doi: 10.3322/caac.21457] [Medline: 29846947]

21. Kaminski MF, Robertson DJ, Senore C, Rex DK. Optimizing the quality of colorectal cancer screening worldwide. Gastroenterology 2020 Jan;158(2):404-417 [FREE Full text] [doi: 10.1053/j.gastro.2019.11.026]

22. Pluta RM. Colonoscopy. JAMA 2011 Mar 16;305(11):1154 [FREE Full text] [doi: 10.1001/jama.305.16.1154]

23. Coriat R, Lecler A, Lamarque D, Deyra J, Roche H, Nizou C, et al. Quality indicators for colonoscopy procedures: a prospective multicentre method for endoscopy units. PLoS One 2012;7(4):e33957 [FREE Full text] [doi:

10.1371/journal.pone.0033957] [Medline: 22509267]

24. Wang L, Mannalithara A, Singh G, Ladabaum U. Low rates of gastrointestinal and non-gastrointestinal complications for screening or surveillance colonoscopies in a population-based study. Gastroenterology 2018 Feb;154(3):540-555.e8. [doi: 10.1053/j.gastro.2017.10.006] [Medline: 29031502]

25. Levin TR, Zhao W, Conell C, Seeff LC, Manninen DL, Shapiro JA, et al. Complications of colonoscopy in an integrated health care delivery system. Ann Intern Med 2006 Dec 19;145(12):880-886. [doi:

10.7326/0003-4819-145-12-200612190-00004] [Medline: 17179057]

26. Pickhardt PJ, Choi JR, Hwang I, Butler JA, Puckett ML, Hildebrandt HA, et al. Computed tomographic virtual colonoscopy to screen for colorectal neoplasia in asymptomatic adults. N Engl J Med 2003 Dec 04;349(23):2191-2200. [doi: 10.1056/NEJMoa031618] [Medline: $\underline{14657426}$ ]

27. Johnson CD, Chen MH, Toledano AY, Heiken JP, Dachman A, Kuo MD, et al. Accuracy of CT colonography for detection of large adenomas and cancers. N Engl J Med 2008 Sep 18;359(12):1207-1217 [FREE Full text] [doi: 10.1056/NEJMoa0800996] [Medline: 18799557]

28. Spada C, Stoker J, Alarcon O, Barbaro F, Bellini D, Bretthauer M, et al. Clinical indications for computed tomographic colonography: European Society of Gastrointestinal Endoscopy (ESGE) and European Society of Gastrointestinal and 
Abdominal Radiology (ESGAR) Guideline. Eur Radiol 2015 Feb;25(2):331-345 [FREE Full text] [doi: 10.1007/s00330-014-3435-z] [Medline: 25278245]

29. Levi Z, Birkenfeld S, Vilkin A, Bar-Chana M, Lifshitz I, Chared M, et al. A higher detection rate for colorectal cancer and advanced adenomatous polyp for screening with immunochemical fecal occult blood test than guaiac fecal occult blood test, despite lower compliance rate. A prospective, controlled, feasibility study. Int J Cancer 2011 May 15;128(10):2415-2424 [FREE Full text] [doi: 10.1002/ijc.25574] [Medline: 20658527]

30. Van Ballegooijen M, Habbema JDF, Boer R, Zauber AG, Brown ML. A comparison of the cost-effectiveness of fecal occult blood tests with different test characteristics in the context of annual screening in the medicare population. In: Technology Assessment Report. Rockville(MD): Agency for Healthcare Research and Quality(US); Aug 9, 2003 :A.

31. Wolf A, Fontham E, Church T, Flowers CR, Guerra CE, LaMonte SJ, et al. Colorectal cancer screening for average-risk adults: 2018 guideline update from the American Cancer Society. CA Cancer J Clin 2018 Jul;68(4):250-281 [FREE Full text] [doi: 10.3322/caac.21457] [Medline: 29846947]

32. Phillipson L, Pitts L, Hall J, Tubaro T. Factors contributing to low readiness and capacity of culturally diverse participants to use the Australian national bowel screening kit. Public Health Res Pract 2019 Mar 06;29(1):e28231810 [FREE Full text] [doi: 10.17061/phrp28231810] [Medline: 30972408]

33. Deding U, Torp-Pedersen C, Bøggild H. The association between immigration status and ineligible stool samples for colorectal cancer screening. Cancer Epidemiol 2018 Dec;57:74-79. [doi: 10.1016/j.canep.2018.10.005] [Medline: 30326395]

34. de Klerk CM, Wieten E, van der Steen A, Ramakers CR, Kuipers EJ, Hansen BE, et al. Participation and ease of use in colorectal cancer screening: a comparison of 2 fecal immunochemical tests. Am J Gastroenterol 2019 Mar;114(3):511-518. [doi: 10.14309/ajg.0000000000000148] [Medline: 30789417]

35. Shin HY, Suh M, Choi KS, Hwang S, Jun JK, Han DS, et al. Higher satisfaction with an alternative collection device for stool sampling in colorectal cancer screening with fecal immunochemical test: a cross-sectional study. BMC Cancer 2018 Apr 02;18(1):365 [FREE Full text] [doi: 10.1186/s12885-018-4290-0] [Medline: 29609647]

36. Ellis RJB, Wilson S, Holder RL, McManus RJ. Different faecal sampling methods alter the acceptability of faecal occult blood testing: a cross sectional community survey. Eur J Cancer 2007 Jun;43(9):1437-1444. [doi: 10.1016/j.ejca.2007.03.019] [Medline: 17475476 ]

37. Koo JH, Arasaratnam MM, Liu K, Redmond DM, Connor SJ, Sung JJY, et al. Knowledge, perception and practices of colorectal cancer screening in an ethnically diverse population. Cancer Epidemiol 2010 Oct;34(5):604-610. [doi: 10.1016/j.canep.2010.05.013] [Medline: 20580631]

38. Le Breton J, Journy N, Attali C, Le Corvoisier P, Brixi Z, Bastuji-Garin S, et al. Improving participation in colorectal cancer screening: targets for action. Prev Med 2012 Nov;55(5):488-492. [doi: 10.1016/j.ypmed.2012.08.004] [Medline: 22926013]

39. Gwede CK, Koskan AM, Quinn GP, Davis SN, Ealey J, Abdulla R, Tampa Bay Community Cancer Network (TBCCN). Patients' perceptions of colorectal cancer screening tests and preparatory education in federally qualified health centers. $\mathbf{J}$ Cancer Educ 2015 Jun;30(2):294-300 [FREE Full text] [doi: 10.1007/s13187-014-0733-8] [Medline: 25249181]

40. Garrett PE, Lasky FD, Meier KL. EP12-A2, user protocol for evaluation of qualitative test performance. In: Approved Guideline-Second Edition. Wayne, Pennsylvania, USA: Clinical and Laboratory Standards Institute; Jan 2008.

41. McEnroe RJ, Magari R, Durham AP, Middle JG, Goldford MD, Pierson-Perry JF, et al. Evaluation of Precision of Quantitative Measurement Procedures. In: Approved Guideline - Third Edition. Wayne, Pennsylvania, USA: Clinical and Laboratory Standards Institute; Oct 2014.

42. Wahba N. An ortho-tolidine hydrochloride test for the detection of occult blood in faeces without dietary restrictions. $\mathbf{J}$ Clin Pathol 1965 Sep;18(5):687-688 [FREE Full text] [doi: 10.1136/jcp.18.5.687] [Medline: 5835456]

43. FDA, Diagnostic Devices Branch, Division of Biostatistics, Office of Surveillance and Biometrics. Reporting results from studies evaluating diagnostic tests. Guidance for Industry and FDA Staff. 2007 Mar 13. URL: https://www.fda.gov/ regulatory-information/search-fda-guidance-documents/ statistical-guidance-reporting-results-studies-evaluating-diagnostic-tests-guidance-industry-and-fda [accessed 2020-04-01]

44. Clark LW, Garrett PE, Martin R, Meyer K. User protocol for evaluation of qualitative test performance. In: Proposed Guideline. Wayne, Pennsylvania, USA: National Committee for Clinical Laboratory Standards; 2000.

45. Beckman Coulter. Hemoccult SENSA. Product Instructions. Brea, CA, USA: Beckman Coulter, Inc; 2015 Jun. URL: https:/ /www.beckmancoulter.com/download/file/wsr-116766/462489EF?type=pdf [accessed 2020-05-14]

46. Lee E, Lee Y. Is it necessary to repeat fecal occult blood tests with borderline results for colorectal cancer screening? Ann Lab Med 2018 Jan;38(1):51-53 [FREE Full text] [doi: 10.3343/alm.2018.38.1.51] [Medline: 29071819]

47. Arana-Arri E, Idigoras I, Uranga B, Pérez R, Irurzun A, Gutiérrez-Ibarluzea I, EUSKOLON Group. Population-based colorectal cancer screening programmes using a faecal immunochemical test: should faecal haemoglobin cut-offs differ by age and sex? BMC Cancer 2017 Aug 29;17(1):577 [FREE Full text] [doi: 10.1186/s12885-017-3555-3] [Medline: 28851318]

48. Libby G, Fraser CG, Carey FA, Brewster DH, Steele RJC. Occult blood in faeces is associated with all-cause and non-colorectal cancer mortality. Gut 2018 Dec;67(12):2116-2123 [FREE Full text] [doi: 10.1136/gutjnl-2018-316483] [Medline: $\underline{30012724]}$ 
49. Chen L, Yen AM, Fraser CG, Chiu SY, Fann JC, Wang P, et al. Impact of faecal haemoglobin concentration on colorectal cancer mortality and all-cause death. BMJ Open 2013 Nov 07;3(11):e003740 [FREE Full text] [doi: 10.1136/bmjopen-2013-003740] [Medline: 24202058]

50. McDonald PJ, Strachan JA, Digby J, Steele RJC, Fraser CG. Faecal haemoglobin concentrations by gender and age: implications for population-based screening for colorectal cancer. Clin Chem Lab Med 2011 Dec 07;50(5):935-940. [doi: 10.1515/CCLM.2011.815] [Medline: 22149740]

51. Rose C, Parker A, Jefferson B, Cartmell E. The characterization of feces and urine: a review of the literature to inform advanced treatment technology. Crit Rev Environ Sci Technol 2015 Sep 02;45(17):1827-1879 [FREE Full text] [doi: 10.1080/10643389.2014.1000761] [Medline: 26246784]

52. Fraser CG, Rubeca T, Rapi S, Chen L, Chen H. Faecal haemoglobin concentrations vary with sex and age, but data are not transferable across geography for colorectal cancer screening. Clin Chem Lab Med 2014 Aug;52(8):1211-1216. [doi:

10.1515/cclm-2014-0115] [Medline: 24637000]

53. Fraser CG, Auge JM, PROCOLON Group. Faecal haemoglobin concentrations do vary across geography as well as with age and sex: ramifications for colorectal cancer screening. Clin Chem Lab Med 2015 Aug;53(9):e235-e237. [doi: 10.1515/cclm-2014-1172] [Medline: 25544746]

54. Navarro M, Nicolas A, Ferrandez A, Lanas A. Colorectal cancer population screening programs worldwide in 2016: An update. World J Gastroenterol 2017 May 28;23(20):3632-3642. [doi: 10.3748/wjg.v23.i20.3632] [Medline: 28611516]

55. Cancer Prevention Group. Taiwan breast, oral cancer, and colorectal cancer screening programs. Cancer Prevention and Control. Taipei, Taiwan: The Health Promotion Administration; 2016 Jan 26. URL: https://www.hpa.gov.tw/Pages/Detail. aspx?nodeid=1051\&pid=5957 [accessed 2020-06-17]

\section{Abbreviations \\ ANOVA: analysis of variance \\ CLSI: Clinical and Laboratory Standards Institutes \\ CT: computed tomographic}

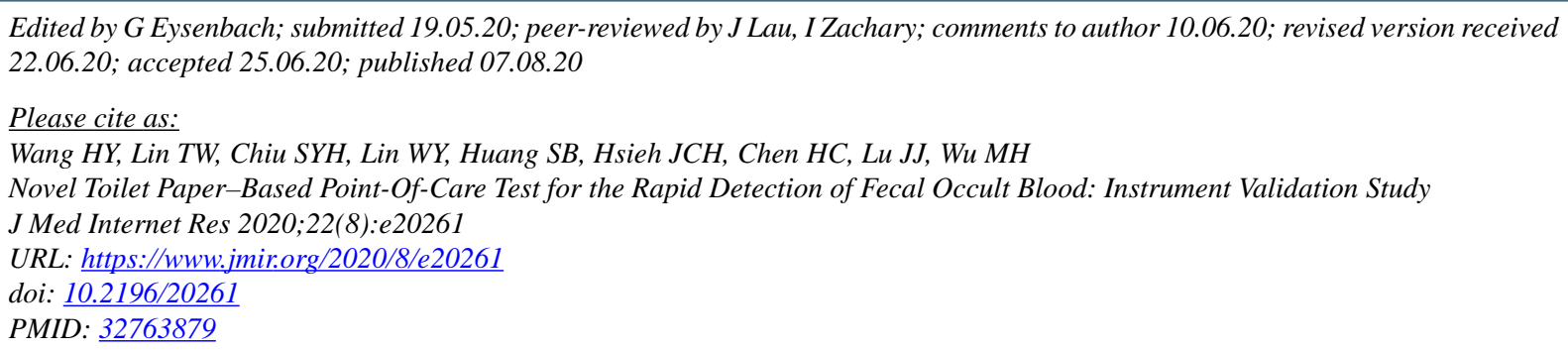

CHsin-Yao Wang, Ting-Wei Lin, Sherry Yueh-Hsia Chiu, Wan-Ying Lin, Song-Bin Huang, Jason Chia-Hsun Hsieh, Hsieh Cheng Chen, Jang-Jih Lu, Min-Hsien Wu. Originally published in the Journal of Medical Internet Research (http://www.jmir.org), 07.08.2020. This is an open-access article distributed under the terms of the Creative Commons Attribution License (https://creativecommons.org/licenses/by/4.0/), which permits unrestricted use, distribution, and reproduction in any medium, provided the original work, first published in the Journal of Medical Internet Research, is properly cited. The complete bibliographic information, a link to the original publication on http://www.jmir.org/, as well as this copyright and license information must be included. 